\title{
UN SOLDADO AL SERVICIO DE LA CORONA. APUNTES A LA OBRA DE DIEGO SUÁREZ CORVÍN
}

\author{
Juan Cerezo Soler \\ (Universidad Autónoma de Madrid)
}

\section{RESUMEN}

La guerra discontinua entre la Corona española y el Imperio Otomano localizada en el norte de África ha dejado numerosos testimonios literarios desperdigados por bibliotecas y archivos. Son, en su mayoría, obras de difícil clasificación, pues el hecho histórico y el dato inventado no siempre aparecen bien diferenciados. Retomamos esta cuestión, constante en el estudio del género autobiográfico, a propósito de una de estas obras sobre el conflicto: la Historia del Maestre último que fue de Montesa, escrita por el soldado Diego Suárez, el Montañés.

PALABRAS CLAVE: autobiografía, Siglo de Oro, norte de África, Imperio Otomano.

\section{A SOLDIER AT THE SERVICE OF THE CROWN. NOTES ON THE WORK OF DIEGO SUÁREZ CORVÍN}

\begin{abstract}
The intermittent war between Spain and the Ottoman Empire developed in North Africa has left several testimonies scattered in libraries and archives. These works are difficult to classify since there is no remarkable difference between historical data and fiction. We return to the debate about one of these narrative works: Historia del Maestre último que fue de Montesa, written by Captain Diego Suarez Montañés.
\end{abstract}

KEY WORDS: autobiography, Golden Age, North Africa, Ottoman Empire. 


\section{INTRODUCCIÓN: UNA GUERRA POR ESCRITO}

La presencia de la Corona española en territorio norteafricano durante los Siglos de Oro suscitó testimonios de muy diverso tipo por parte de quienes vivieron en sus carnes la tensión de un estado de guerra constante ${ }^{1}$. La creación, así como la distribución y recepción, de estos testimonios estuvo sujeta al momento histórico que la propició, es decir, que fueron más abundantes en los períodos de mayor crudeza bélica y escasearon cuando las relaciones entre los dos bandos se mantuvieron templadas ${ }^{2}$. Este vínculo entre el momento histórico y las obras provoca, inevitablemente, una difusión de sus límites genéricos, lo que ha desorientado a buena parte de la comunidad investigadora, que no siempre ha sabido si abordar su estudio desde presupuestos historiográficos o literarios. Como bien apuntan Bunes Ibarra y García Arenal, la situación en la frontera norteafricana se testimonia gracias a

la literatura de creación o de imaginación, pero también a las fuentes escritas de carácter histórico o geográfico. Hay veces que resulta difícil separar entre ambas. Porque la literatura de ficción incorpora y utiliza elementos históricos y gira a menudo en torno a acontecimientos concretos de gran impacto contemporáneo, y porque escritores como Cervantes (aunque también otros) incluyen en sus obras no solo personajes de existencia real, sino descripciones de ciudades, modos de vida, etc., de los que a menudo fueron testigos presenciales. Y porque la literatura que

\footnotetext{
1 Según la cronología del conflicto propuesta por García Arenal y Bunes Ibarra, pueden distinguirse tres etapas: la primera "De 1497 a 1516, como continuación de la Guerra de Granada, los españoles conquistan un rosario de plazas desde el Estrecho a Trípoli para abandonar la expansión africana a favor de los asuntos de Italia"; la segunda "De 1516 a 1559 la lucha es sobre todo contra los corsarios de Argel en los momentos y ocasiones en que dan un respiro las grandes empresas europeas" y la tercera "De 1559 a 1580 la lucha será sobre todo contra los turcos de Estambul cuya presencia en el Mediterráneo se ha hecho mucho más opresiva”. Orán, conquistada en 1509, permanecerá como emplazamiento fronterizo español hasta el final del siglo XVIII. Mercedes García Arenal y Miguel Ángel de Bunes Ibarra, Los españoles y el norte de África. Siglos XV-XVIII (Madrid: MAPFRE, 1992), 1416. El año de 1580 marcaría el fin "oficial" del conflicto con las treguas entre Felipe II y la Sublime Puerta. Decimos "oficial" porque, bajo este aparente alto el fuego, se siguió desarrollando un tipo de guerra corsaria entre las urbes magrebíes y las costas españolas, en un intercambio creciente de hostilidades, al pairo de treguas y tratados entre los gobiernos. Esta continuación velada de la lucha es la que hace a Sola hablar de "guerra de los 300 años", en clara referencia al tramo que va de 1492 a 1792. Guerra, por lo tanto, discontinua, de intensidad cambiante hasta la capitulación de Orán, que coincide, además, con la fecha del último cautivo español documentado en Berbería. Emilio Sola, «Carlos V y la Berbería. El contexto de la frontera mediterránea en la época de Carlos V» en Carlos V, los moriscos y el islam, coord. M.J. Rubiera (Alicante: Universidad de Alicante, 2001), 334.

2 "Las crónicas y relatos, salvo algunas excepciones que citaremos más adelante, nacen siempre al calor de los acontecimientos. Cuando esta llama se extingue, cuestión que acaece con demasiada prontitud, el tema se olvida". Miguel Ángel de Bunes Ibarra, Mercedes García Arenal y Victoria Aguilar Sebastián, Repertorio bibliográfico de las relaciones entre la península Ibérica y el norte de Africa: (siglos XV-XVI) Fuentes y bibliografía (Madrid: CSIC, 1989), 36.
} 
pudiéramos llamar "científica" no siempre separa lo real de lo imaginario, y siente predilección por los temas que habrían de convertirse en tópicos literarios ${ }^{3}$.

Estos restos testimoniales del conflicto, escritos a menudo por los mismos protagonistas, han estado durmiendo en distintos archivos y bibliotecas, y solo parcialmente y de forma desgajada se han ido conociendo títulos, nombres y volúmenes. Si bien es cierto, como ya se ha dicho, que son obras de muy distinto -e indeterminado- signo genérico, no ha de olvidarse el factor común a todas ellas: "la preocupación y narración de las situaciones que se vivían en el Norte de África"4. Tampoco hay que olvidar que son obras que, en su justo marco literario, comparten panorama con las composiciones de tema morisco, de viajes, de soldados y cautivos ${ }^{5}$. Se trata, en todo momento, de un paisaje literario vinculado a las relaciones entre cristianismo e islam en clave de conflicto, y no puede conocerse en profundidad sin un vistazo a los distintos tipos de documentos, históricos o no, que lo conforman: historias generales y descripciones topográficas -que constituyen la faceta más tratadística de esta literatura-; relaciones de sucesos, crónicas del cautiverio y de sus redentores; memoriales ${ }^{6}$, autobiografías - de cualquier tipo- y, finalmente, ficciones stricto sensu, novelas, poemas y piezas teatrales que toquen de alguna manera el asunto ${ }^{7}$. Pese a los esfuerzos críticos de las últimas décadas por sistematizar todo este vasto conjunto escrito, aún está por establecerse una nómina, si no completa, sí lo bastante

\footnotetext{
${ }^{3}$ García Arenal y Bunes Ibarra, Los españoles y el norte de África, 99.

${ }^{4}$ Bunes Ibarra, García Arenal y Aguilar Sebastián, Repertorio bibliográfico, 18.

${ }^{5}$ García Arenal y Bunes Ibarra, Los españoles y el norte de Africa, 103.

${ }^{6} \mathrm{El}$ memorial de servicios, género brillantemente defendido por Francisco Estévez Regidor como "la necesidad de hilvanar relaciones merced a sus propiedades autodiegéticas" configurando "una suerte de moda literaria entre los muy numerosos soldados que acudían a la Corte a solicitar remuneración por sus servicios, plazas, destinos o ascensos, acogiéndose al fuero militar". Francisco Estévez Regidor, "Asedio genérico a las relaciones soldadescas del Siglo de Oro", en Scripta manent. Actas del I Congreso Internacional de Jóvenes Investigadores Siglo de Oro, ed. C. Mata Induráin y A. J. Sáez (Pamplona: Universidad de Navarra, 2011), 180.

7 George Camamis es el primero en comentar la literatura de cautiverio y se da cuenta de la convivencia que se da entre los elementos idealizados y los históricos, pues en la literatura del siglo "podemos distinguir dos tipos de cautiverio muy diferentes: uno basado en la realidad histórica del Siglo de Oro, con sus cautiverios en África del Norte y Constantinopla [...] y otro muy relacionado con el tema tal como aparece en la novela griega y bizantina". George Camamis, Estudios sobre el cautiverio en el Siglo de Oro (Madrid: Editorial Gredos, 1977), 14. El testigo es recogido por Antonio Rey Hazas, que algunos años más tarde, señalará que "una considerable dosis de historicidad y verismo entraba en las filas de la narrativa quinientista de corte aventurero-caballeresco. La ficción pura de las novelas de caballerías podía encontrar así una alternativa más cercana a la realidad”, «Introducción a la novela del Siglo de Oro I. Formas de narrativa idealista», Edad de Oro 1 (1982): 67; finalmente, Miguel Ángel Teijeiro Fuentes mencionará, partiendo del inédito caso del Viaje de Turquía, que "será seguido con cierta insistencia en la literatura española de principios del siglo XVII por otros personajes de la ficción en un conjunto de relatos en los que el cautiverio en poder de los turcos se convierte en el incidente principal de la acción", Moros y turcos en la narrativa áurea. El tema del cautiverio (Cáceres: Universidad de Extremadura, 1987), 29.
} 
amplia como para dar cuenta cabal del fenómeno; una nómina ${ }^{8}$, decimos, que permita reconstruir con fidelidad esta parcela de la historia literaria de nuestro Siglo de Oro?.

En la ya debatida tensión entre realidad histórica y literatura se enmarcaría la figura de Diego Suárez Corvín, apodado "el Montañés", soldado asturiano que vivió durante casi toda su vida adulta al servicio de la monarquía en uno de los emplazamientos fronterizos más importantes, la plaza de Orán, punta de lanza del Imperio hispánico frente a la amenaza turco-berberisca. Este autor nos legó una obra escrita tan abundante como desatendida y que, por su propia fisonomía literaria trasciende, creemos, las pretensiones historiográficas de su autor. El texto de Diego Suárez se nos revela como un documento valiosísimo al margen de sus méritos innegables, por otro lado- como fuente histórica, pues su lectura sosegada permite intuir unas costuras literarias cuya calidad aún está por descubrir. Es autor de la Historia del Maestre último que fue de Montesa, obra probablemente escindida de una mayor que aspiraba a ser algo así como una Historia General sobre el Norte de África; de unos Avisos importantes para la Magestad del Rey y de no pocas composiciones poéticas, algunas incluso publicadas en vida. El presente estudio se orientará, pues, a ponderar los elementos literarios y su convivencia con el dato informativo dentro de su obra, argumentando en favor de la existencia de un discurso que supera, a lo que creemos, lo puramente historiográfico.

Primero se situará a Diego Suárez en su contexto a través de unas breves notas biográficas; también se intentará arrojar luz sobre el estado en que se encuentra la transmisión manuscrita de su obra, particularizando el comentario sobre dos volúmenes que se guardan en la Biblioteca Nacional de Madrid. Una vez asentado el escenario en el que esta figura vivió y escribió, se abordará el núcleo del estudio: el análisis de su obra de referencia, La historia del Maestre último que fue de Montesa y de su hermano don Felipe de Borja. Se pondrán en comparación distintos pasajes escritos por Suárez en aras de constatar las diferencias entre los dos tipos de discurso que en ellos conviven: el cronístico y el literario. Es importante matizar que esta cualidad literaria, en el caso del Montañés, no responde a un intento expreso de creación de ficciones,

\footnotetext{
${ }^{8}$ Un importante conjunto de documentos ha sido recopilado y catalogado, primero, por Carlos Rodríguez Joulia Saint-Cyr, Bibliografía menor hispanomusulmana (Madrid: Dirección General de Archivos y Bibliotecas, 1970) para los textos impresos. Años más tarde vería la luz el ya citado trabajo de Bunes Ibarra, García Arenal y Aguilar Sebastián, Repertorio bibliográfico, en el que se recopilan documentos impresos y manuscritos.

${ }^{9}$ Lo que escribe Bunes Ibarra sobre los relatos de cautivos bien puede aplicarse a todo el conjunto de obras, pues "Al mismo tiempo que se escriben crónicas, poemas y obras de teatro celebrando los triunfos ante los musulmanes, comienzan a publicarse relatos y novelas que tienen como argumento los padecimientos de los españoles apresados por los moradores del otro lado del Mediterráneo. Este tipo de obras, muy usuales en la nómina de la historiografía menor y las relaciones de sucesos, suelen detenerse en la descripción de las torturas, malos tratos y tormentos que los captores dan a sus capturados. La nómina de los padecimientos se amplía en las autobiografías y memorias, en las crónicas de los redentores o, incluso, en las historias generales sobre África". Miguel Ángel de Bunes Ibarra, "Las crónicas de cautivos y las vidas ejemplares en el enfrentamiento hispano-musulmán en la Edad Moderna” Hispania Sacra 45, n. 91 (1993): 68.
} 
todos los datos que recoge son históricos y nada de lo que cuenta escapa a la realidad. El autor está, más que creando una ficción, ficcionalizando una realidad, pues aunque su obra carezca de elementos imaginativos e irreales, sí se pueden percibir en ella ciertos mecanismos de reelaboración de los hechos, sutiles tergiversaciones interesadas que, además, vienen muy marcadas por intenciones particulares ${ }^{10}$.

Por último, se verá que todos los tramos en los que percibimos este pulso literario están cobijados bajo la experiencia autobiográfica del autor, lo que hace pertinentes algunos comentarios sobre el género autobiográfico en el Siglo de Oro y, al tiempo, permite situar a Diego Suárez en una estela de autores en los que, de manera marcadamente especial, se encarna la tensión entre historia y literatura a través de tus testimonios en primera persona.

\section{I. "SIENDO TAN INCLINADO A LA PLUMA COMO A LAS ARMAS"}

Diego Suárez llega a la plaza de Orán el 7 de abril del año 1577. Forma parte de una remesa de soldados enviados desde la península a los emplazamientos norteafricanos. Así relata el mismo autor su llegada a Orán, ya en las últimas páginas de su Historia del Maestre último que fue de Montesa:

Por el mes de abril del año 1577 allegó a Orán la gente de guerra y fábrica que su Majestad había man[da]do proveer para aquellas plazas para ayuda de su guarda y fortificaciones, entre la cual gente de guerra fui yo uno. Donde serví veintisiete años continuos sin hacer baja ni ausencia de una de las compañías de infantería ordinarias de Orán en que primero me reformaron, cuyo capitán nombraban Pedro Fernández de Guzmán ${ }^{11}$.

Situado en el continente que será su hogar durante casi tres décadas, el Montañés empieza no como "gente de guerra", sino como "gente de fábrica", colaborando en calidad de peón en la construcción y fortificación de las defensas. Cuatro años más tarde se le permite la incorporación a filas como soldado de infantería. Forma su familia dentro de las murallas de Orán ${ }^{12}$, participa en todos los trabajos y actividades que le exige su condición de soldado -cabalgadas, incursiones,

\footnotetext{
${ }^{10}$ De la misma forma que hay un vínculo indisoluble entre estas obras y la coyuntura histórica que relatan, se puede percibir una intención eminentemente propagandística en todas ellas, dirigidas a mover la voluntad y la conciencia del receptor a propósito del conflicto contra el islam. Miguel Ángel de Bunes Ibarra, La imagen de los musulmanes y del Norte de Africa en la España de los siglos XVI y XVII. Los caracteres de una hostilidad (Madrid: CSIC, 1989), 152.

${ }^{11}$ Diego Suárez Corvín, Historia del Maestre último que fue de Montesa, ed. Miguel Ángel de Bunes Ibarra y Beatriz Alonso Acero (Valencia: Diputación de Valencia, 2004), 571.

${ }^{12}$ Junto a los militares residentes en Orán, "aparece un grupo muy heterogéneo que, bajo la denominación de «personas particulares», reúne a individuos de diversa extracción y ocupación que, aun sin ser militares propiamente dichos algunos de ellos, sí mantienen una estrecha vinculación con la guarnición de las plazas". Beatriz Alonso Acero, Orán-Mazalquivir, 1589-1639: Una sociedad española en la frontera de Berbería (Madrid: CSIC, 2000), 75; Orán es, además, "el único enclave magrebí donde se crea una sociedad civil dentro de las murallas", lo que permitía el asentamiento de familias en el presidio y con ello se garantizaba el servicio prestado por los soldados. Suárez Corvín, Historia del Maestre, 12.
} 
asaltos, exploraciones, capturas- y en torno a 1590 se le concede un puesto en la organización de la sacristía de San Bernardino de Orán, lo que le permite cambiar las tensiones sobre el terreno por el estudio y el trabajo de despacho. Es aquí donde Suárez puede, por primera vez, dar rienda suelta a la inclinación por las letras que tiene desde que es niño y que menciona insistentemente a lo largo de toda su obra. Este puesto le permite, además, acceder a fondos documentales que hoy se consideran perdidos ${ }^{13}$. Es en esta época cuando concibe e inicia su proyecto más ambicioso: redactar una historia general del Norte de África, una obra que sirva como "crónica de la presencia española en Berbería" verá la luz en vida del autor y aun en nuestros días permanece inédita y fragmentada ${ }^{15}$. Uno de los capítulos de este monumental escrito nos ha llegado con el nombre de Historia del reyno de Tremecen y Orán y se inaugura con un pequeño introito autobiográfico en el que el soldado afianza su autoridad y consolida su credibilidad frente al lector, tal como mandaban los cánones en obras de materia histórica ${ }^{16}$.

En cuanto al resto de datos biográficos, todo -lo más importante, al menosha sido ya señalado en estudios anteriores al nuestro: en 1604 consigue una dispensa para abandonar el presidio norteafricano y es cuando empieza su periplo cortesano en busca de un editor que corra con los gastos de la publicación de su obra. Este tramo de la biografía del Montañés merece ser reseñado, aprovechando que el mismo autor ha dejado toda una relación manuscrita, paso a paso, de los avatares que vivió para encontrar sufragio y apoyo en la publicación.

Llegó a la ciudad de Toledo en 1604, donde cayó enfermo durante todo el mes de mayo. Convaleciente aún, consiguió llegar a la corte, a la sazón situada en Valladolid, donde localizó su posible primer mecenas: Juan de Borja. Tras dejarle noticia de su obra, se fue a Asturias para arreglar algunos asuntos de su hacienda. En 1605 volvió a Valladolid y de allí a Madrid, donde elaboró una dedicatoria al duque de Gandía, Carlos de Borja. Ir a Gandía se convirtió, entonces, en "blanco de su quimera" "17; y llegó en 1608. Lamentablemente, no logra en esta ocasión audiencia con el duque, aunque sí recibe referencias de su hermano, don Baltasar de Borja,

13 Suárez Corvín, Historia del Maestre, 14.

${ }^{14}$ Ibidem. Poco más adelante los editores escriben que "Juan León el Africano, Diego de Haedo, Luis de Mármol Carvajal y Diego Suárez conforman una tetralogía sin la que sería imposible interpretar la historia del Magreb en los siglos XVI y XVII".

15 Para un conocimiento en profundidad de las informaciones documentales y las noticias bibliográficas, ver Miguel Ángel de Bunes Ibarra, "Diego Suárez Montañés, cronista y testigo de la historia de Orán-Mazalquivir" en Orán. Historia de la Corte Chica, coord. Miguel Ángel de Bunes y Beatriz Alonso Acero (Madrid: Polifemo, 2011), 323-368 y la introducción a la edición citada.

${ }^{16}$ Así justifica Diego Suárez la redacción de su autobiografía, según Berbrugger: "Comme il est nécessaire, pour apprécier l'oeuvre, et connaitre la valeur intrinsèque de l'écrivain, jusqu'à maintenant inconnu, qui va nous servir de guide, nous commencerons par discuter de son individualité. Lui-même nous aidera dans cette tâche; car, outre les faits personnels qu'il s'èmeça et là dans son livre; il consacre, au débout de celui-ci, une auto-biographie d'une quarantaine de pages que nous allons analyser, en nous attardant surtout sur les passages qui concernent le point de vue africain". Adrien Berbrugger, "Mers el Kebir et Oran de 1509 à 1608 d'après Diego Suarez Montañes" Revue Africaine 56 (1866): 112.

${ }^{17}$ Suárez Corvín, Historia del Maestre, 65. 
clérigo valenciano. Sin dudarlo se pone en camino hacia Valencia. El canónigo, dada su sacra condición, no podía apadrinar una obra que tocase puntos bélicos y de caballerías, por lo que remitió al asturiano y su obra a don Pedro Centellas, un caballero pariente de los Borja. Yendo a su encuentro, le halló "loco, sin juicio ni acuerdo ninguno, retirado en su casa muchos días había"18. Suarez se vio obligado, entonces, a seguir en Valencia mendigando cuantos apoyos pudiera encontrar para la publicación del volumen. Cae "enfermo de calenturas" y pierde todo el dinero que había cobrado por sus antiguos servicios. Le asistieron durante esta enfermedad viejos compañeros de campaña y, tras su recuperación, vuelve con renovadas fuerzas a lograr la ansiada publicación. Viajó hacia Alicante con una carta para don Pedro de Borja, hijo del Maestre al que hace referencia la historia que ha escrito. Don Pedro corriera con los gastos de la impresión si no estuviese, en ese momento, pasando por estrecheces económicas. Se pondría, eso sí, en contacto con Tomás de Borja, arzobispo de Zaragoza. Cierto problema judicial permitió que varios caballeros de la Orden de Montesa fueran al encuentro de don Pedro coincidiendo con Suárez Corvín. Todos vieron y leyeron su historia pero "sintieron mucho no poderla amparar y sacar luego a luz"19. Llegado este punto se reencontró con su familia, arruinado y notablemente irritado por los sinsabores que su obra le estaba ocasionando; experimentó, incluso, la "determinación de quemar o echar el libro en el mar”. Fue de nuevo a Alicante donde malvendió todo lo que tenía, de allí a Sicilia, donde se quedaría desde 1609, desempolvando de vez en cuando la historia del Maestre, puliendo el estilo y ampliando detalles. En 1616 fue a Nápoles y ahí es donde se trunca la redacción. No deja de sorprender la inclusión de estas entradas en el epílogo, a modo de diario en tiempo real, sobre la búsqueda de mecenazgo para la publicación de su obra; el propio escritor se justifica diciendo que añadió "este sobretrabajo en confianza de que en algún tiempo podría salir a la luz y tener yo algún premio de mis trabajos y gastos" 20 . El hecho es que, pese a sus esfuerzos por ver su obra en letra de molde, se quedó manuscrita e inédita hasta 1889, fecha de la primera edición encargada por la Sociedad de Bibliófilos Españoles.

Todos los manuscritos de Diego Suárez están dispersos por varias bibliotecas: la Historia del reyno de Tremecen y Orán se encuentra en Aix de Provence ${ }^{21}$, si bien un fragmento de la misma, concretamente el libro cuarto, duerme en la Biblioteca Nacional de España. Se trata del manuscrito Mss/8594, un tomo de unas 157 páginas. La redacción ofrece un aspecto limpio y cuidado, no se perciben apenas tachones, errores ni cualquier marca de escritura apresurada, antes bien, podría

\footnotetext{
18 Ibídem, 66.

${ }^{19}$ Ibídem, 68.

${ }^{20}$ Ibídem, 71.

21 "Durante décadas se creyó que este manuscrito estaba perdido, y exclusivamente teníamos referencias a sus contenidos por los historiadores que utilizaron los fondos de la Biblioteca General de Argel durante la época de dominio francés de esta parte del Magreb. La gran obra de Suárez fue comprada en los primeros años del siglo XIX en el levante español y llevada a Francia, para luego ser trasladada a Argelia, y reintegrarse nuevamente en los archivos nacionales galos sitos en Aix de Provenze después de la independencia de la colonia". Bunes Ibarra, "Diego Suárez Montañés", 327.
} 
decirse que estamos ante una copia hecha con conciencia de destinarse a la imprenta: así lo muestra no solo la pulcritud del texto, sino también el respeto por los márgenes -destinados a albergar anotaciones del propio autor-, o la colocación de los títulos, escritos en tamaño de cuerpo mayor y distribuidos en forma de copa, emulando el texto impreso. El ejemplar presenta una foliación moderna hecha a lápiz y solo aisladamente se perciben signos de foliaciones anteriores, agrupadas, sobre todo, en las últimas hojas. La encuadernación es holandesa, típica del siglo XIX. Como peculiaridad del ejemplar hay que señalar que hay una carta en el f. 155 en la que Diego Suárez reclama cierta cantidad de dinero, en concreto, noventa y dos ducados. Bunes Ibarra y Alonso Acero, los últimos editores de la Historia del Maestre último que fue de Montesa, señalan que se trata de una carta autógrafa ${ }^{22}$, en coherencia con la información del Inventario General de Manuscritos de la Biblioteca Nacional.

En esta misma biblioteca se guarda otro documento interesante: el manuscrito Mss/7882, cuyo contenido está íntegramente transcrito en la edición que manejamos. Es un tomo con una encuadernación en pergamino típica del siglo XVII que alberga otra cuidadísima redacción, esta vez de la Historia del Maestre; en total, unas 425 hojas foliadas a lápiz. De aspecto limpio, interlineado espaciado, con los márgenes y sangrías debidamente respetados, está distribuido tal y como se concibió para su publicación, con los poemas laudatorios, la tablatura de los contenidos, la "Relación del travaxo y costa questa historia | tiene hecho a su Auctor en las deligen | cias que hizo para sacarlo a luz en España" y el "Prólogo al benévolo lector" debidamente colocados. Procede de la biblioteca del Conde de Cervellón.

Estos dos tomos presentan condiciones muy similares, tanto en el plano físico como en el paleográfico. Si se tiene por autógrafa la carta que cierra el Mss/8594, puede aventurarse que también lo sea el resto del tomo, así como el Mss/7882. Parece claro que es una única mano la que recorre los dos manuscritos, sin intervención de segundos copistas. Así lo señala la semejanza en el trazado de algunas grafías: la $p$ interrumpe su caída con un corte en forma de arpón y la $M$ presenta, en la primera de sus aristas, un trazo ornamental hacia la izquierda. Esto son ejemplos extraídos tras un primer vistazo apresurado, demostrar esta condición de texto autógrafo exigiría un análisis paleográfico más sosegado y un estudio más profundo del estado documental en que se encuentra la obra del asturiano, objetivos que exceden, de momento, el propósito de estas páginas.

\section{LA VERDAD Y SU RECREACIÓN LITERARIA}

El objetivo principal del Montañés es, en todo momento, ofrecer una imagen panorámica y lo más completa posible de las condiciones de vida en la frontera sur del Imperio. La pretensión de su obra, en una primera instancia, sería informativa. Suárez, en tanto que intenta ser cronista, escribe desde el precepto sobre el género histórico. Él mismo afirma -con especial insistencia al comienzo de su obra- que cuando cogió la pluma para iniciar la redacción, trabajó

\footnotetext{
22 Suárez Corvín, Historia del Maestre, 20.
} 
[...] todo lo que me fue posible en no apartarme ni salir un punto del camino y sagrada virtud de la verdad, que en todo el discurso de esta historia apuré y averigüé muy bien, testificándola con muchas fidedignas personas que vieron y manejaron todo lo que en ellas escribo, y es común general voz en la dicha Orán y su reino de Tremecén ${ }^{23}$.

La búsqueda de la "verdad" se constituye casi como una obsesión, motor que guía y espolea a todo autor con aspiraciones historiográficas. Esto, por definición, obligaba a nuestro capitán asturiano a posicionarse contra todas las obras de asunto declaradamente ficticio,

En que, segundamente, suplico a todos aquellos a quien más esta historia agradare y pertenezca, me amparen y defiendan de las venenosas lenguas [...] por ignorancia bruta de no alcanzar a gustar de historias de que otros discretos y prudentes gustan, y desean leer libros verdaderos y de gastar tiempo en ellos y no en marañas patrañeras de que otros tienen apetito y reciben gusto, como de Olivante de Laura, El caballero de Febo, El caballero de la Cruz, Don Quijote de la Mancha y otros semejantes libros. De [los] que no se saca fruto de buenos ejemplos para imitar lo bueno y huir de lo malo [...] no estiman cada cosa por lo que es, ni alcanzan que es muy mayor trabajo y peligro inquirir y hacer una historia de cosas verificadas de guerra estando a la cara testigos de ella, que forjar y componer otra de mentiras afeitadas con estilo y color de la verdad, como hay muchas, de que muchos gustan y pierden el tiempo sin fruto ninguno, ni se les pega nada que puedan ejemplificar con verdad, como podrán desprender los que la presente historia leyeren ${ }^{24}$.

Este rechazo a las novelas de ficción caballeresca por el componente de irrealidad idealizada que entrañan está en perfecta sintonía con la teoría historiográfica de su época y sus principales referentes, tales como Juan Luis Vives, Ambrosio de Morales, López de Velasco o Cabrera de Córdoba ${ }^{25}$. La mención al Quijote en esta apología de la verdad histórica evidencia la lectura superficial que hizo el Montañés de la obra de Cervantes: no solo no capta su intención burlesca hacia los libros de caballerías, sino que pasa por alto aquellos pasajes de la obra en los que se habla de "verdad" como axioma indiscutible en la creación de crónicas históricas; tampoco fue capaz de entender el juego de voces narrativas -la figura del historiador arábigo, Cide Hamete- dentro del contexto historiográfico en que se pergeñó todo el

\footnotetext{
23 Suárez Corvín, Historia del Maestre, 75-76.

${ }^{24}$ Ibídem, 77.

${ }^{25}$ Estos teóricos suelen asemejar la inclusión de elementos ficticios con la falta de rigor histórico. Todo lo que sea destinado a la recreación del lector está condenado a no perdurar dada su inutilidad informativa, como redacta Juan Páez de Castro: "así se alteran los vulgares con libros que llaman de caballerías y lloran y ríen y se enamoran y se aíran". "Memorial de las cosas necesarias para escribir Historia», apud. Alfredo Alvar Ezquerra, "Cómo hacer Historia en tiempos de Cervantes: propuestas historiográficas" Edad de Oro 30 (2011): 10.
} 
experimento cervantino ${ }^{26}$. Con todo, si de algo sirve el pasaje es para ilustrar el conocimiento de Suárez sobre los rasgos que ha de tener una obra según la receta canónica para el desempeño de cualquier labor cronística.

La Historia del Maestre último que fue de Montesa está dividida en dos partes, la primera narra con detalle el período de gobierno de don Pedro Galcerán de Borja en Orán y Mazalquivir, desde 1567 hasta 1572; la segunda se centra en la figura de su hermano, don Felipe de Borja, que toma el control de las plazas tras el traslado del primero a España, desde 1572 a $1573^{27}$. El tramo cronológico recogido alcanza los seis años. Los sucesos que narra son muy anteriores a la llegada del autor a Orán, por lo que se vio obligado a realizar trabajos de documentación a conciencia por no faltar a ese ideal de verdad que todo historiador debía perseguir: "Y habiendo recogido para esto, con no poco trabajo mío, muchas verdaderas relaciones de viejos, inquiriendo y averiguando de uno en otro, y por otras memorias y escrituras, todo lo que pasó en tiempo de cien años en aquellas plazas" ${ }^{28}$. Las fuentes utilizadas para la creación de su obra son de dos tipos: textuales y orales; y con ellas suple la falta de conocimiento vivencial de los hechos que relata ${ }^{29}$.

$\mathrm{Al}$ tratar eventos que no pudo presenciar, ha de erigir su narración sobre una sólida investigación documental. Ello no significa, por otro lado, que la obra sea un simple documento notarial, limitado a la sucesión de hitos y exento de material autobiográfico. Todo lo contrario. Si algo justifica este análisis es, precisamente, la continua tensión entre dos registros narrativos diferentes a lo largo de todo el libro: uno basado exclusivamente en el dato objetivo e histórico que quiere presentar, y otro sostenido sobre su experiencia propia. El primero es un registro aséptico, desapasionado, en el que la enumeración de nombres, la descripción minuciosa y el dato científico constituyen el cuerpo central. El segundo, por el contrario, sustituye ese conocimiento informativo con una narración cercana, encarnada en la vivencia

${ }^{26}$ Cervantes, en su calidad de polifacético escritor, manejó también el registro de "Historiador de verdad, no narrador de aventuras o novelas de caballerías, sino epistemólogo de la creación de este peculiar - por ser subjetivo- género literario, o de esta ciencia humanística que siempre anda en pos de la verdad, aunque la escriba un sujeto". Ibídem, 7.

${ }^{27}$ Una estupenda relación de los hechos políticos que se vivieron dentro de la Orden de Montesa durante este período puede leerse en Fernando Andrés Robres, "Galcerán de Borja, Felipe II y la tardía incorporación del maestrazgo de la orden de Montesa a la Corona”, en Iglesia y sociedad en el Antiguo Régimen, ed. Enrique Martínez Ruiz y Vicente Suárez Grimón (Las Palmas de Gran Canaria: Universidad de Las Palmas de Gran Canaria, 1995), 409-420.

${ }^{28}$ Suárez Corvín, Historia del Maestre, 74.

29 Alfredo Alvar Ezquerra, "Cervantes, la epistemología de su tiempo y otros lugares comunes" Edad de Oro 25 (2006): 9-34. En este estudio el autor extrae una serie de presupuestos historiográficos a partir del pensamiento cervantino inscrito en la segunda parte del Quijote. El segundo de estos aforismos es que "sólo son dignos de ser historiados los hechos pasados y conclusos". Esto supone un problema para el historiador, que tiene que narrar con veracidad unos hechos que no ha vivido. Para ello se consolida la investigación documental como herramienta de trabajo y se inician importantes proyectos archivísticos: "Por tanto, para escribir historia veraz era necesario renovar las fuentes de información. Las fuentes nuevas fueron los archivos, en los que se custodiaban los papeles reales, pero cada vez más otros documentos. Y si se guardaban ahí, no era para que se pudrieran, sino para que fueran usados por la posteridad, o cuando fuera preciso", Ibídem, 14. 
del propio autor. La descripción que antes se presentaba completa, escrupulosa y muy rica en detalles perderá aquí rasgos de minuciosidad para tornarse, de alguna forma, más literaria. Los personajes que durante el primer tramo registro quedan reducidos a la simple mención de nombres y fechas, en los pasajes más literarios aparecen significados por sus propias acciones, sentimientos y sufrimientos ${ }^{30}$, y sus historias marcadas por elementos como el heroísmo, la valentía o el sacrificio. El lector puede percibir perfectamente que en la obra del soldado asturiano conviven el tratado informativo sobre Orán y Mazalquivir con la descripción de las costumbres y la narración de las acciones llevadas a cabo; acciones que, como veremos, se presentan empapadas de su experiencia personal ${ }^{31}$ a pesar de desarrollarse muchos años antes de su llegada al presidio norteafricano.

Los primeros capítulos de esta Historia comienzan con las descripciones de los emplazamientos en los que se desarrolla el relato. El discurso tendrá aquí, como ya anticipamos, un marcado carácter tratadístico, centrado en el objeto de descripción:

Tiene Orán hasta ochocientos vecinos, y cinco iglesias do hay sacramento. La mayor, matriz de aquellas plazas, nombrada Santa María de la Victoria, y tres conventos: San Francisco, Santo Domingo y el de la Merced, redención de cautivos, y el hospital, nombrada su iglesia San Bernardino. Demás de esto hay dos ermitas dentro de la ciudad, en lo más fuerte de ella, de la advocación de San Miguel y de Santiago. Hay asimismo, fuera de la ciudad, entre ella y la mar, otras tres ermitas: San Roque, San Sebastián, y de Nuestra Señora del Carmen ${ }^{32}$.

Esta descripción objetiva pasará del interior de las plazas al exterior, comentando con generosidad de detalles el terreno donde están asentados los presidios y ofreciendo, incluso, las medidas en leguas que hay desde un punto geográfico a otro:

\footnotetext{
${ }^{30}$ Según esto, y dado que el cautiverio es un tema recurrente en la obra de Suárez Corvín, podría incluirse esta Historia del Maestre en el macro marbete de obras de cautiverio comentado por Bunes Ibarra, "Las crónicas de cautivos". Todas estas obras presentan como rasgo común la narración, sin escatimar detalles, de los padecimientos que sufrían los cautivos. "Las razones por las que se escriben este tipo de relatos son obvias y evidentes, de la misma manera que el predicamento que tuvieron en la sociedad del momento", Ibídem, 70; esto es, respondían a una necesidad propagandística mediante la cual todo el país pudiera ver ejemplos reales de sacrificio durante una guerra tan fastidiosa para la población civil, sobre todo la que residía en las costas.

${ }^{31}$ La vinculación de la figura del autor con su propia narración define el tipo de obra: "Para ilustrar el hecho de que «la función autor no se ejerce de un modo universal y constante sobre todos los discursos», Foucault sitúa el quiasmo que, según él, «se produjo en el siglo XVII, o en el XVIII» y que ve el cambio de ese régimen de asignación de los textos entre los discursos científicos y los discursos «literarios» [...] mientras los enunciados científicos cimientan su autoridad sobre su pertenencia a un «conjunto sistemático» de proposiciones, y no sobre las propiedades de un autor particularizado, los discursos «literarios» «ya no pueden ser recibidos más que dotados de la función-autor»", Roger Chartier, Libros, lecturas y lectores en la Edad Moderna (Madrid: Alianza Universidad, 1993), 63.

32 Suárez Corvín, Historia del Maestre, 96.
} 
Desde cabo Falcón a cabo Figal se miden seis leguas por mar y por tierra, en que no se hace ensenada ni punta ninguna [...] De cabo Figal a cabo de One se contienen catorce leguas de travesía de mar, golfo de una grande ensenada que allí se hace, casi de facción redonda, que entra en la tierra más de cuatro leguas dentro de los dichos dos cabos. [...] Más adelante, contra poniente siete leguas, en lo último de la ensenada, entra en el mar el otro río, llamado Risgol. ${ }^{33}$

El asturiano trata, además, aspectos de interés secundario pero que completan la información del territorio que describe. Habla de la flora, la fauna, agricultura y economía. En estos tramos hace gala de un notable conocimiento de la terminología especializada, enumerando por extenso especies animales, vegetales, métodos, etc., proyectando una erudición que, real o no, le sirve para apuntalar la veracidad de su relato:

A los montes de este reino cubren diferentes árboles, como son mayormente lantiscos, sabinas, espinos de dos o tres maneras y, en algunas partes, alcornoques y encinas, algarrobos. [...] No se crían en el dicho reino ni en toda África osos, lobos carniceros, venados, gamos, corzas, revezas, martas, lobos cervales, ni hardas [...] En el río de Orán y algunas otras partes se crían y toman anguilas de buen comer, empero truchas ni lampreas no las hay en África. En el mar que baña y acompaña este reino se pesca y matan varias formas de peces como habemos visto en tiempo de treinta años en la marina de Orán y Mazalquivir: sargos, alachas, arañas, caballas, lechas, lizas, jureles, carameles, bodiones, zalemas, bogas, sardinas, galludos, cañavotas, pintarrojos, cornudas, espadartes, abadejos, golondrinas, bonitos, palominos, samas, bacoretas, morenas, acedías, delfines, brecas, guitarras, azulejos, angelotes, besugos, caballas, cabrillas, berrugatos, atunes, burros, congrios, corvinas, cochinos, chovas, zorros, doncellas, chupas, emperadores, dentudos, milras, ostras, estrellas, pachones, dagustines, gallinas, tortugas, galápagos, lenguados, gallos, gatos, melvas, mantas, mulos, peces rey, meros, marrajos, raya, pargos, pescadas, tinturillas, xivias, salmonetes, sapos, tollo, resquicios, ranas, tordos, espetones, calamares, langostas, pámpanos, y otras muchas formas y nombres de peces. Algunas veces se muestran ballenas en este mar y allegan bien acerca de su orilla, mas no hay quien las mate, como bacemos en Asturias $^{34}$.

Nótese que entre toda esta exhibición terminológica, el autor va dejando pequeñas menciones sobre su persona. Diego Suárez es consciente de que su texto ha de ser completo y riguroso, no debe dejar fuera ningún detalle que pueda, llegado el caso, ser considerado relevante; pero al mismo tiempo debe atender, como autor, las necesidades de credibilidad frente al lector. Por ello se inmiscuye, alude paulatinamente a sí mismo y a su experiencia personal en el desarrollo de los tramos topográficos más descriptivos, adentrándose poco a poco en el tipo de escritura autorreferencial que ya venía de largo en la escena narrativa de su tiempo. Si bien tales alusiones podrían, en cierto modo, menoscabar la cualidad científica del texto,

\footnotetext{
33 Ibídem, 105-106.

${ }^{34}$ Ibídem, 109-111. El resaltado es nuestro.
} 
sobre todo en lo tocante a la misma materia geográfica que describe, serán un refuerzo importante cuando lo que esté describiendo sea el día a día en el presidio, así como las acciones bélicas que se llevaron a cabo. Escribirá, pues, como el que vio y vivió lo que cuenta, con una autoridad fuera de toda duda, asentada para entonces gracias a estas pequeñas menciones autorreferenciales.

No obstante, y pese a las marcas autobiográficas que anticipan el tono literario que está por venir, lo que tenemos aquí es la elaboración de un volumen rigurosamente historiográfico, según el canon de la época en la escritura cronística, tal como revela la inclusión hasta de las fuentes manejadas para el recaudo de datos. Se sabe que manejó noticias, escritos y documentos de muy diverso tipo, y algunos de ellos incluidos en el relato a modo de apéndices documentales. Con estos apéndices aumenta, pues, la veracidad del tratado mediante la aportación de pruebas auténticas: "Por las nuevas que cada día corrían de que el enemigo turco quería bajar otra vez sobre aquellas plazas, y así le mandó despachar y despachó con el título y provisión siguiente" ${ }^{\prime 35}$. A este pasaje le sigue un extenso escrito del rey Felipe II con la patente de capitán general de Orán, dirigida a don Pedro Galcerán de Borja. Otro apéndice documental se incluye no mucho más adelante: un texto con el contenido del pleito homenaje, que era la ceremonia mediante la cual el Maestre recibía el gobierno de las plazas norteafricanas ${ }^{36}$.

Quizá, otro de los recursos usados por Suárez en pos de esta misma veracidad sea la continua mención a personajes reales que, seguramente, serían reconocidos por el lector medio español:

De los cuales unos y otros ramos de esta nación mahometanos, naturales africanos y advenedizos alárabes [...] cuyos nombres de los alárabes más principales son Uled Talha, Uled Abdala, Uled Muza, Uled Brahen, Uled el Hajez, Uled Bent Jafar, Bent Acoror, Uled el Hamida, cuya cabeza más principal de cada linaje de estos se llaman jeque ${ }^{37}$.

[...] en el dicho cargo de capitán general de Orán y su reino, por real provisión, don Diego Fernández de Córdoba, tercer marqués de Comares [...] Siéndole venida la licencia, dejó en su lugar, por la misma real orden, en el gobierno de aquellas plazas y reino, a don Luis de Bocanegra de Belmonte, caballero del hábito de Alcántara, [...] Para adonde, en la primavera del año 1575, proveyó por capitán general de aquellas plazas y reinos a don Martín de Córdoba, caballero del hábito de Santiago [...] Y teniendo necesidad de verse con su Majestad, le envió a pedir licencia estando con las armas en las manos en la conquista y quietud del reino de Portugal. Y, concediéndosele, le envió su Majestad [a] aquellas plazas en su lugar a don Pedro de Padilla, caballero del hábito y orden de Santiago [...] Por el mes de abril del año 1581 volvió el mismo marqués don Martín de Córdoba segundamente por capitán general de estas plazas y reinos ${ }^{38}$.

\footnotetext{
35 Ibídem, 201.

${ }^{36}$ Ibídem, 207.

${ }^{37}$ Ibídem, 116.

${ }^{38}$ Ibídem, 563-572.
} 
Suficiente como muestra. Todas estas informaciones, zanjado el asunto principal de la obra, sirven para soldar con datos puramente cronológicos el relato del Montañés ${ }^{39}$.

Vistos y comentados los capítulos y pasajes en los que el discurso no sale del tono informativo, elaborando -como parece ser la intención primera- una crónica absolutamente prototípica; es pertinente extraer ahora los tramos de mayor riqueza literaria. Estos son los capítulos en los que el discurso de Suárez no se limita a la narración del hecho histórico, a su plasmación sin más pretensión que la descriptiva, sino a su reelaboración, regodeándose por tramos en escenas en las que la buena práctica historiográfica no obligaba y excediendo, así, la intención cronística que ya hemos presentado. Esta recreación se empieza a percibir, entre otras cosas, en el lenguaje utilizado. El soldado asturiano deja paulatinamente de parafrasear documentos y testimonios, va abandonando poco a poco las apabullantes listas terminológicas y la simple enumeraciónde nombres y fechas para entrar en la narración de acciones y hechos de armas llevados a cabo por sus protagonistas. El estilo se vuelve directo y la prosa fluida, más ágil, dejando ver al trasluz el verdadero ingenio literario del Montañés, un ingenio, ya se ha señalado, que compensa una supuesta falta de formación con una experiencia vívida sobre el terreno en la lucha contra el musulmán.

Empezando por la calidad descriptiva del relato, se percibe que de la plasmación inicial de simples detalles geo-topográficos, el autor avanza hacia una descripción de las plazas centrada en la actividad, sobre todo militar, de sus habitantes. Describe así algunas formas en las que se organizan y llevan a cabo las llamadas cabalgadas, incursiones relámpago a caballo para apresar cautivos y posesiones del enemigo:

Siempre que salen los capitanes generales de Orán con su ejército de guerra para hacer presas [y] cabalgadas en los moros enemigos es de ordinario por aviso y medio de espías, que son siempre en una de dos maneras. La primera es cuando algún moro súbdito a otro recibe alguna injuria que no se puede vengar, la sufre y disimula de presente, para vengarse más de lleno por mano de los cristianos [...] Otros moros, para hacer esto mejor a su salvo, en recibiendo la injuria se van luego de aquellos aduares a otros, y de allí andan siempre a la mira para venirles a vender a Orán ${ }^{40}$.

Poco a poco va centrando la atención del lector en las actividades de los personajes implicados, en este caso, en el método de alcanzar logros militares utilizando el espionaje dentro de las filas enemigas. La descripción, que cada vez va

\footnotetext{
39 Recuerdan a los apéndices incluidos en una obra bastante más temprana e igualmente desconocida en su época: el Viaje de Turquía. En ella, junto al diálogo hay un tramo titulado Turcarumorigo, en la que se suceden los nombres de todos los emperadores de Turquía. Este apéndice ha sido tradicionalmente considerado como el menos rico desde un punto de vista literario, es decir, el que más participaba de la fórmula tratadística en la que el texto se limita a presentar una sucesión de datos históricos, hasta el punto de que uno de sus editores actuales llegó a excluirlo en su edición de la obra. Viaje de Turquía, ed. Fernando García Salinero (Madrid: Cátedra, 2010).

${ }^{40}$ Suárez Corvín, Historia del Maestre, 143.
} 
tomando un cariz más costumbrista, también toca las formas de organización estratégica:

En cuyas jornadas va ordinariamente el capitán general en la vanguardia, en la medianía de la frente del escuadrón, en igualdad con las banderas y estandartes de a caballo. Y a un tiro de ballesta más adelante van los adalides con el espía guiando [...] y se nombra luego asimismo un caudillo, capitán o alférez, plático soldado que quede por cabo y gobierno de todo ${ }^{41}$.

O la gestión de todo lo conseguido tras la incursión, siempre que la jornada haya concluido con éxito:

Primeramente, en el siguiente día del en que entra la presa en Orán, se hace el aprecio y tasación de ella, de esclavos y bestias de carga, y lo mismo del ganado grande o menor si se ha traído [...] Y siendo vendida toda la presa y hecha la suma de lo que monta, se saca primeramente la costa que ha hecho, pagando la toma de los propios esclavos, veinte reales por cada uno ${ }^{42}$.

Mucho más intensos son los pasajes centrados en las batallas concretas contra el moro. Aquí, Diego Suárez romperá toda distancia con su discurso -si es que alguna quedaba- para echar mano de cuantos recursos tenga a su alcance y ofrecer un relato vivo, con verdadera intención recreativa, de las escenas bélicas, presentándolas al lector en toda su crudeza. Empezando por la calidad de la soldadesca cristiana:

Tantas vi[c]torias como ha sido la pequeña escuadra militar de Orán y Mazalquivir. Do sólo allí les han castigado siempre valerosamente, como los mismos turcos lo saben y es notorio en todo el mundo. Do es averiguada cosa que todas las veces que han llegado por tierra a vista de aquellas plazas, con fuerzas de sitios o sin ellos, gruesas y menores mahalas o bandas de turcos han vuelto siempre con la mano en la cabeza y grande menoscabo y afrenta de su nombre, sin otras muchas escurribandas y rociadas que les hemos dado en toda la costa por levante y poniente de Orán, en que les hemos maltratado con muertes y cautiverios de muchos de ellos. Algunas veces ha sucedido, con solo la furia de arcabucería de tierra, rendirles en las galeras y galeotas en la mar ${ }^{43}$.

Sigue con la narración de eventos militares puntuales, cuya riqueza en detalles acerca la pluma montañesa, casi, al estado de materia novelesca:

Salió el Maestre muy maltratado de la barranquera porque rodó hasta lo hondo de ella. Donde nos certificaron personas fidedignas que pasaron más de veinte soldados por [en]cima del mismo Maestre, de tropel, por no poderse tener y ser el paso angosto. Y

\footnotetext{
${ }^{41}$ Ibídem, 147.

42 Ibídem, 194.

43 Ibídem, 127.
} 
lo mismo por [en]cima de otros soldados, que se arrojaron y arrollaron delante, hasta lo más hondo, y con todo eso el Maestre daba voces:

-‘Adelante, españoles!'

Sacáronle de allí bien molido y cansado, y cubierto todo de lodo y barro, el rostro y ropa, y vomitando por causa de que, al rodar, se había mareado la cabeza. Y con ser, como era, hombre de grande cuerpo, y [que] en días mostraba el ánimo como un mozo de treinta años y con alegre semblante, como si por él tal cosa no pasara, y lleno de risa. Y decía a los soldados que le sacudían y quitaban el barro:

- 'Dejadlo estar, hermanos, que esas son las medallas de la guerra y granjerías de ella’44.

Aparte del tono pretendidamente heroico de la anécdota, es reseñable la forma directa con que cita las palabras del Maestre. De seguro, Suárez tuvo que conocer la escena a través de sus conversaciones con los soldados veteranos que la vivieron, pero sería arriesgado afirmar que esas fueron, exactamente, las palabras del Maestre, como deja entrever el relato. Lo mismo puede leerse, quizá algo mejor, en el capítulo $\mathrm{XV}$, donde tiene lugar una pequeña competición lúdica entre uno de los soldados de Juan de Austria y otro residente en el presidio norteafricano. Al finalizar, tiene lugar el siguiente parlamento

- ¡Hallado habéis la horma de vuestro zapato en Mazalquivir’.

- 'iQue sea posible que en esta grajera', dijo don Vasco, 'haya quien me gane y tire tan bien y desenfundadamente [sic], lo que no he hallado en toda España! ¡Válate el diablo por soldado, carne de perro ahumada!'

Respondió el señor don Juan:

- '¿No veis que la tiene enjuta, hecha de bizcocho y malpasar y correosa, no co[mo] la vuestra y la mía, hechas de manjar blanco y almondiguillas?'

Y con esto volvió su Alteza la cara al alcaide de la fuerza, pidiéndole aquel soldado para llevarle consigo en las galeras.

- 'No permitirá vuestra Alteza'45.

El pasaje continúa, y la conversación, nada breve, se alarga lo suficiente como para aventurar que se trata de una refacción del propio Montañés, que ha sometido el hecho histórico a un proceso de elaboración literaria en el que se configura un paisaje, un ambiente, una anécdota y una conversación. Bien nos parece que el asturiano esté sometiendo la batería de anécdotas de las que se nutre -históricas todas, sin duda alguna- a una recreación, introduciendo detalles, ordenándolas a placer y según su propia forma de exposición. Al fin y al cabo, la veracidad de este pasaje se sostiene en todo momento sobre la memoria de terceros, algo que, desde luego, en términos textuales puede ser bastante falible.

Más tramos se pueden encontrar en los que se ponen palabras en boca de los personajes en un descarado estilo directo, como si fueran citas exactas de lo que en verdad se dijo. En el capítulo IX, titulado "De cómo el Maestre de Montesa allegó a

\footnotetext{
44 Ibídem, 237.

45 Ibídem, 262.
} 
Orán y recibió el cargo de aquellas plazas de mano de Hernán Tello de Guzmán”, el lector se encuentra con una escena en la que el antiguo Maestre, Hernán Tello y otros capitanes se sientan y disfrutan de una copiosa comida.

Y, sobremesa, le encomendó grandemente Hernán Tello los soldados, gente de guerra de aquellas plazas, en una plática que hizo del tenor siguiente:

'Yo he militado desde mi tierna edad en servicio de la Corona de España en Italia, Flandes, Hungría, en que me nacieron las barbas y canas entre pláticos’46.

Continúa el discurso del militar durante las tres páginas siguientes. Esta vez, Suárez Corvín no está refiriendo una frase concreta, o una conversación breve, fácilmente asimilable por el auditor aunque difícil de transmitir de una forma textual. Ahora lo que está haciendo es incluir una arenga, un discurso que, como todo ejercicio de oratoria, muere en el mismo momento de su pronunciación. Y lo redacta no en forma de paráfrasis, o de resumen, sino en estilo explícitamente directo. Un pasaje como este pondría sin duda en guardia al lector suspicaz, conocedor de la epistemología historiográfica del siglo, pues la repetición textual, letra por letra, de un discurso del que no ha quedado constancia escrita por ningún lado no hace sino restar veracidad al relato. $\mathrm{Y}$, aun con menoscabo de esa misma veracidad desde el punto de vista preceptivo, no se nos negará que este formato expresivo enriquece literariamente el texto, aportándole ritmo, fluidez y, por qué no, un punto de solemnidad a la narración.

En otros pasajes, Diego Suárez ofrece una descripción impregnada de colores de la experiencia bélica. Le llama poderosamente la atención el comportamiento de las tropas cristianas cuando están en medio de una incursión, por lo que introduce el ojo narrativo en el interior de la compañía. Describe, con pasmosa maestría, el silencio que reina en la marcha hacia una misión:

Es cosa de ver que, en saliendo por las puertas de Orán a hacer presas o cualquier otro servicio del castigo de los enemigos o en escoltas de provisiones que se meten, enmudecen todos, que no les oirán una palabra en muchas leguas que caminen. En que se marcha con un silencio de forma que no se oye otra cosa que el tropel del patear de la caballería y bagaje. Que, a no llevar este bestiamen, pasarían, a manera [de] decir, como las aves por el aire, sin sentirlo los enemigos [...] Que por no dar voces los soldados que de noche se pierden de la conserva del escuadrón, mangas o volante, donde van le tocan. Que verdaderamente parece la voz del pájaro de este nombre que llaman cárabo del monte, que en Asturias llaman coruxas, de que hay infinidad dando voces de noche por las montañas y los bosques ${ }^{47}$.

Este silencio, así descrito, favorece la tensión propia del asunto que se está relatando. Hay, además, un detenimiento interesante en los detalles menores, como el patalear de los caballos, que aumenta la plasticidad de la descripción. Por último, la

\footnotetext{
46 Ibídem, 214.

47 Ibídem, 145-146.
} 
insistente referencia a elementos conocidos por el propio Diego Suárez -esa especie de ave asturiana que menciona- constituye el mejor ejemplo de la incursión de la figura del autor en el devenir narrativo de su propia obra.

Hay, en esta Historia, determinadas escenas de lucha real en las que se logran idénticas cotas de verismo, amparadas en la habilidad del autor para manejar los distintos recursos cromáticos que le ofrecen los contrastes entre luz y sombra:

Es cosa de ver cuando se da Santiago en los aduares enemigos, invocando principalmente este santo patrón de las Españas y el del nombre que se lleva, porque no se maten unos a otros en la bulla de la refriega, mayormente si hace oscuro. Porque muchas veces el centellear de las espadas y alfanjes de los moros dan luz en la pendencia furiosa que se trae, a sólo cuchilladas y lanzadas, mayormente si son caballeros y el aduar se ha cercado bien ${ }^{48}$.

En este sentido, el escenario de constante combate contra los asentamientos turco-berberiscos proporciona una inagotable fuente de material sobre el que novelar. Algunos de los pasajes más ricos del texto corviniano pueden encontrarse en la relación de los sufrimientos inherentes a las acciones militares. Aquí la redacción se vuelve encarnada y de una notable crudeza

Fue el sitio largo, las baterías y asaltos muy a menudo, y grandísima el hambre y necesidades que allí se padecieron, en forma que no tenían ya los sitiados caudal ni valor para sufrir el peso de la larga calamidad del sitio, en que estaban ya tan necesitadísimos y cansados y con solo un asno, jumento sarnoso, que les había quedado de muchos que habían comido y les quedaba ahora este solo para comer. Estaban ya flacos y debilitados los pocos soldados que habian quedado, que ponia espanto a quien les veía. Porque todos, o los más de ellos, tenian las mejillas derechas desquijaradas y acardenaladas del continuo tirar y fuerza de las coces de los arcabuces y mosquetes en las prolijas baterías y asaltos [...] Martín de Córdoba, y salir con él al campo a dar una encamisada al enemigo, al sueño del alba, para hacerle retirar o morir todos allí [y] acabar de una vez, partiendo sus almas en sole $[\mathrm{m}]$ ne procesión para el cielo ${ }^{49}$.

Más todavía cuando el autor trae a colación el tema del cautiverio, tema que el mismo Suárez conoció no solo por las relaciones de sucesos y noticias impresas que informaban de los eventos fronterizos más sonados, sino de primera mano: le eran familiares los cautivos cristianos, participó en sus liberaciones, es casi seguro que más de un compañero de campaña cayó apresado por el enemigo y conocía bien, en fin, la captura de esclavos y cautivos en las ya mencionadas cabalgadas. No es de extrañar, por tanto, que imprima buena parte de su experiencia personal en la obra, mostrando la crueldad de sus enemigos con un lujo de detalles difícil de igualar por otros autores:

\footnotetext{
48 Ibídem, 151.

${ }^{49}$ Ibídem, 190-191.
} 
Los cuales, como venían con las armas en las manos y los nuestros les salieron a recibir de la misma forma, se comenzó una brava refriega de tierra y mar, peleando valerosamente de ambas partes, de tal modo que los nuestros tuvieron la galeota rendida desde afuera, a fuerza de arcabucería. Y sin duda la tomaran, porque no quedó en ella quien pelease ni moviese remo.

A este tiempo salió, debajo de cubierta, un turco desnudando una damasquina o alfanje, con que cortó de presto un brazo a un cautivo cristiano del remo por junto al hombro, con el cual comenzó a dar golpes a los demás cristianos de la cadena, hasta que les hizo alargar la galeota de tierra ${ }^{50}$.

Del mismo modo, no oculta su sorpresa ante determinadas evasiones de cautivos, cada cual más espectacular que la anterior:

Allegaron a Orán y su playa doce cautivos que venían huyendo de Argel en una muy pequeña barquilla que ellos mismos habían hecho fuera de Argel. Que puso espanto a toda la gente que la vio, de pequeño bajel que era, como una cuna a manera de decir como nos certificaron muchas personas fidedignas que lo vieron. Que apenas cabían en él los doce cautivos, y de que hubiesen podido navegar de Argel a Orán más de sesenta leguas de mar, y más de invierno, que siempre está soberbio y tempestuoso ${ }^{51}$.

$\mathrm{Y}$, finalmente, a todo lo señalado hay que añadir la presencia -tímida al principio, constante y absoluta después- del autor, no ya como narrador sino como pseudo-protagonista a lo largo de todo el relato. Diego Suárez certifica continuamente la veracidad de lo que narra a través de continuas alusiones a su experiencia personal. Este pulso primopersonal explicita la intencionalidad de la obra, intencionalidad a la que responde el formato narrativo, la descripción, la distribución del contenido y, en definitiva, toda la configuración del texto que escribió. Para Diego Suárez, esta campaña militar en África del norte es

La cosa más necesaria de conquista que hoy tiene el señorío de España, a los quicios de la puerta, a que nunca ha querido apretar con diligencia, a toda furia apretando aquella famosa ladronera; a donde se puede decir con verdad [que] han llevado los turcos más de quinientas mil personas cautivas en diferentes tiempos y ocasiones, y otros tantos millares de ducados robados y por redenciones desde el año $1515^{52}$.

En coherencia con gran parte de la producción literaria de su época, Suárez dedica sus esfuerzos a mover las voluntades políticas en España y conseguir que se inviertan más recursos en la lucha contra la coalición turco-berberisca. A partir de

50 Ibídem, 232-233.

${ }^{51}$ Ibídem, 234. Estas evasiones tenían mucha resonancia en la sociedad española, tanto en la residente en Berbería como en la peninsular. Ricardo González Castrillo, "Cautivos españoles evadidos de Constantinopla en el siglo XVI" Anaquel de estudios árabes 22 (2011): 265-278; José Antonio Martínez Torres, "Europa y el rescate de cautivos en el Mediterráneo durante la temprana Edad Moderna" Espacio, tiempo y forma. Serie IV. Historia moderna 18-19 (2005-2006): 71-85; García Arenal y Bunes Ibarra, Los españoles y el norte de Africa, 234.

52 Suárez Corvín, Historia del Maestre, 125-126. 
aquí, la mención a su experiencia como soldado activo en el terreno hostil es continua, pues es la mejor certificación histórica de que todo lo escrito ha sucedido, es real y, mucho más importante, que sigue sucediendo en la época en que el autor todavía busca la publicación de su historia: "Lugar poblado de moros, como muchas veces hemos ido a saquear, y allí se dan las órdenes de lo que se ha de hacer" (p. 147), "Cuando los soldados de Orán florecían, en tiempo de mi milicia en aquellas plazas" ( $\mathrm{p}$. 151), "antes de volver a Orán, como sucedió en tiempo del Maestre de Montesa y del duque de Cardona en aquel reino, de que yo soy testigo en tiempo de mi milicia en ép' (p. 153) Y fórmulas como estas se extienden con prolijidad a lo largo y ancho de toda la obra.

Este recurso es, y terminamos, útil en la medida en que permite la presentación de la historia no solo como un compendio de datos veraces, históricos y ciertos, sino también de una enorme actualidad. El contenido autobiográfico, amén de constante, sirve para unir en la mente del receptor del Siglo de Oro -si lo huboel hecho pasado con la situación y la necesidad del presente, insertando al asturiano en la corriente literaria de tipo propagandístico que pobló las imprentas españolas, sobre todo, en los momentos de mayor hostilidad.

\section{CONCLUSIÓN: "DICHOSA ASTURIAS DE OVIEDO SANTA, PUES DISTE UN HIJO TAL Y VIRTUOSO"53.}

Con lo comentado quedan consolidados, si no todos, al menos buena parte de los rasgos literarios de la obra del asturiano. Por supuesto, el campo de análisis queda abierto a que aportaciones futuras den cuenta de nuevos giros y mecanismos utilizados por el Montañés en la configuración de su Historia del Maestre último que fue de Montesa. Obra que, a pesar de sus indudables carencias desde el punto de vista poético, no soporta, a lo que creemos, la lectura guiada por el simple interés histórico. La cantidad de recursos recreativos analizados revelan, como poco, una intención estética, acaso en convivencia con la historiográfica, lo que permite entender la obra como uno de los testimonios más sugerentes sobre los que cualquier interesado en las tensiones entre verdad y poesía puede trabajar. A caballo entre el documento histórico y la ficción literaria, es una obra casi prototípica del contexto de su creación, como se ha mencionado al principio, en el que pueden encontrarse, sin mucha dificultad, entradas similares.

Mencionemos algunos, a modo de colofón: la obra publicada bajo el ala de Diego de Haedo pero que, tras algunos estudios en las postrimerías del siglo XX, parece claro que responde a la autoría de Antonio de Sosa ${ }^{54}$; la Topografía e bistoria general de Argel. Como se sabe, la segunda mitad de esta obra la ocupan una serie de diálogos centrados en los padecimientos de los cautivos en Berbería. Estos diálogos

\footnotetext{
${ }^{53}$ Soneto de don Diego de Cabrera y Alarcón a Diego Suárez Corvín, incluido entre los poemas laudatorios al inicio de la obra, 55 .

${ }^{54} \mathrm{La}$ propuesta y primera argumentación a favor de Antonio de Sosa es de Camamis, Estudios sobre el cautiverio.
} 
están presididos en su totalidad por un pulso firmemente literario, en estas prosas se recrean situaciones reales -con personajes reales, el mismo Cervantes será el protagonista de varios pasajes- pero inmersas en una corriente que exagera, mitifica, tergiversa, adapta y reelabora el dato histórico ${ }^{55}$.

Menos conocida y más lejana en el tiempo es la obra de don Pedro Barrantes Maldonado. Su Diálogo entre Pedro Barrantes Maldonado y un cavallero estrangero: en que cuenta el saco que los turcos hizieron en Gibraltar y el vencimiento y destruyción que la armada de España bizo en la de los turcos. Año 1540, publicada en 1566, puede verse "como ejemplo de la deformación de la realidad y como medio de reflexión de las formas de representación de los hechos en la España del Quinientos"56.

Finalmente, no nos resistimos a comparar la figura de Diego Suárez Corvín con la de otro soldado escritor, también asturiano, que vivió durante el siglo XVII. Autor de la Relación de la vida, el capitán Domingo de Toral y Valdés firma una autobiografía en la que se hace palpable la misma tensión entre información histórica y creación literaria ${ }^{57}$ que vertebra el presente estudio. Tanto Suárez Corvín como Toral de Valdés imprimen en sus relatos históricos buenas dosis de literatura, siempre bajo el auspicio de su experiencia personal. Este escribe una autobiografía en su sentido más riguroso, aquel impregna de autobiografía una biografía ajena, pero los dos se introducen en el contenido de sus relatos como los que vivieron de primera mano aquello que cuentan. Uno es crítico, el otro complaciente, pero los dos se dirigen hacia las instancias políticas y militares bajo las que lucharon ${ }^{58}$. Diego Suárez, queda claro, no presenta ninguna actitud crítica, antes bien, resulta palmario que al buscarla publicación de su texto, necesitaba congraciarse con determinados estamentos y caer en gracia dentro del ámbito cortesano; escribe, pues, una obra para el enaltecimiento público de una persona concreta, agasajo del que espera, sin duda, conseguir algún beneficio.

Concluyendo. Diego Suárez Corvín, soldado asturiano destinado a luchar en Orán durante el último cuarto de siglo XVI, es el autor de una obra cuya relevancia tiene que trascender el terreno historiográfico -campo en el que su utilidad y su

\footnotetext{
${ }^{55}$ Khadija Boudal, "Realidad histórica o ficción literaria del cautiverio en el Siglo de Oro. El Diálogo de la captividad de don Fray Diego de Haedo" (Tesis doctoral, Universidad Autónoma de Madrid, 1990).

56 Ana María Carabías Torres, "Turcos contra católicos. Barrantes Maldonado y la deformación interesada de los hechos militares" Tiempos modernos 19 (2009).

${ }^{57}$ Esto es así desde las primeras, y prácticamente únicas, aportaciones críticas a la figura de Toral y Valdés. "A Serrano y Sanz le interesaba tan solo establecer si la Relación era suficientemente fidedigna para que pudiera ser útil al historiador. Pope, en cambio, se centra en la construcción literaria del texto, en los objetivos personales que persigue su autor y en la visión del mundo que lo caracteriza, y este es el camino que nosotros también tenemos que recorrer". Alejandro Cassol, "Entre historia y literatura: la autobiografía del capitán Domingo de Toral y Valdés (1635)" en V Actas. AISO (1999): 310-311.

58 "Sus virtudes de modestia y orgullo se oponen continuamente a la codicia y a la ambición que rigen la conducta de los comandantes del ejército español. Es realmente considerable la cantidad de críticas, en general bien fundamentadas, que Toral dirige a los responsables de las actividades militares. Se pone en tela de juicio la moralidad, bien escasa, del virrey, el descuido y la presunción de algunos oficiales o la sed de poder y la envidia hacia los colegas que causan perjuicio al ejército todo", ibídem.
} 
importancia son innegables- para ocupar el hueco que le corresponde en la historia de la literatura, pues se sitúa justo en el cambio entre dos épocas literarias definidas: una en la que tanto el moro y el turco como el cautivo aparecen en su versión más idealizada; y otra en la que están marcados por el conflicto, revestidos de realismo descarnado y presentados al público con toda la fuerza trágica que esta penosa guerra político-religiosa provocó. 


\section{REFERENCIAS BIBLIOGRÁFICAS}

Fuentes

Anónimo, Viaje de Turquía, ed. Fernando García Salinero (Madrid: Cátedra, Letras Hispánicas, 2010).

Suárez Corvín, Diego, Historia del Maestre último que fue de Montesa y de su hermano don Felipe de Borja, ed. Miguel Ángel de Bunes Ibarra y Beatriz Alonso Acero (Valencia: Diputación de Valencia, 2004).

Suárez Corvín, Diego, Historia del Maestre último que fue de Montesa y de su hermano don Felipe de Borja, la manera cómo gobernaron las memorables plazas de Orán y Marzalquivir, reinos de Tremecén y Túnez. [Manuscrito], BNE, Mss/7883.

Suárez Corvín, Diego, Historia de Berbería. Sitio imperial sobre Argel. Libro IV [Manuscrito], BNE, Mss/8594.

\section{Estudios}

Alonso Acero, Beatriz, Orán-Mazalquivir, 1589-1639: Una sociedad española en la frontera de Berbería (Madrid: CSIC, 2000).

Alvar Ezquerra, Alfredo, "Cervantes, la epistemología de su tiempo y otros lugares comunes" Edad de Oro 25 (2006): 9-34.

Alvar Ezquerra, Alfredo, "Cómo hacer Historia en tiempos de Cervantes: propuestas historiográficas” Edad de Oro 30 (2011): 7-17.

Andrés Robres, Fernando, "Galcerán de Borja, Felipe II y la tardía incorporación del maestrazgo de la orden de Montesa a la Corona" en Iglesia y sociedad en el Antiguo Régimen, ed. Enrique Martínez Ruiz y Vicente Suárez Grimón (Las Palmas de Gran Canaria: Universidad de Las Palmas de Gran Canaria, 1995): 409-420.

Berbrugger, Adrien, "Mers el Kebir et Oran de 1509 à 1608 d'après Diego Suarez Montañes" Revue Africaine 56 (1866): 111-128 / 197-207.

Boudal, Khadija, "Realidad histórica o ficción literaria del cautiverio en el Siglo de Oro. El Diálogo de la captividad de don Fray Diego de Haedo"(Tesis doctoral, Universidad Autónoma de Madrid, 1990). 
Bunes Ibarra, Miguel Ángel, La imagen de los musulmanes y del Norte de Africa en la España de los siglos XVI y XVII. Los caracteres de una hostilidad (Madrid: CSIC, 1989).

Bunes Ibarra, Miguel Ángel, "Las crónicas de cautivos y las vidas ejemplares en el enfrentamiento hispano-musulmán en la Edad Moderna" Hispania Sacra 45, n. 91 (1993): 67-82.

Bunes Ibarra, Miguel Ángel, "Diego Suárez Montañés, cronista y testigo de la historia de Orán-Mazalquivir" en Orán. Historia de la Corte Chica, ed. M. A. de Bunes y Beatriz Alonso Acero (Madrid: Polifemo, 2011): 323-368.

Bunes Ibarra, Miguel Ángel, Mercedes García-Arenal y Victoria Aguilar Sebastián, Repertorio bibliográfico de las relaciones entre la peninsula Ibérica y el norte de Africa: (siglos XV-XVI) Fuentes y bibliografía (Madrid: CSIC, 1989).

Camamis, George, Estudios sobre el cautiverio en el Siglo de Oro (Madrid: Gredos, 1977).

Carabías Torres, Ana María, "Turcos contra católicos. Barrantes Maldonado y la deformación interesada de los hechos militares" Tiempos modernos 19 (2009).

Cassol, Alessandro, "Entre historia y literatura: la autobiografía del capitán Domingo de Toral y Valdés (1635)", V Actas. AISO (1999): 308-318.

Chartier, Roger, Libros, lecturas y lectores en la Edad Moderna (Madrid: Alianza Universidad, 1993).

Estévez Regidor, Francisco, "Asedio genérico a las relaciones soldadescas del Siglo de Oro", en Scripta manent. Actas del I Congreso Internacional Jóvenes Investigadores Siglo de Oro (IISO 2011), ed. Mata Induráin, Carlos y Sáez, Adrián J., (Pamplona: Servicio de Publicaciones de la Universidad de Navarra, 2011): 173-184.

García Arenal, Mercedes y Miguel Ángel de Bunes Ibarra, Los españoles y el norte de África. Siglos XV-XVIII (Madrid: MAPFRE, 1992).

González Castrillo, Ricardo, "La pérdida de la Goleta y Túnez en 1574, y otros sucesos de historia otomana, narrados por un testigo presencial: Alonso de Salamanca" Anaquel de estudios árabes 3 (1992): 247-286.

González Castrillo, Ricardo,"Cautivos españoles evadidos de Constantinopla en el siglo XVI" Anaquel de estudios árabes 22 (2011): 265-278. 
Martínez Torres, José Antonio, "Europa y el rescate de cautivos en el Mediterráneo durante la temprana Edad Moderna" Espacio, tiempo y forma. Serie IV. Historia moderna 18-19 (2005-2006): 71-85.

Rey Hazas, Antonio, "Introducción a la novela del Siglo de Oro I. Formas de narrativa idealista" Edad de Oro 1 (1982): 66-105.

Sola, Emilio, "Carlos V y la Berbería. El contexto de la frontera mediterránea en la época de Carlos V", en Carlos V, los moriscos y el islam, ed. M. J. Rubiera (Alicante: Universidad de Alicante, 2001): 321-235.

Teijeiro Fuentes, Miguel Ángel, Moros y turcos en la narrativa áurea. (El tema del cautiverio) (Cáceres: Universidad de Extremadura, 1987).

Recibido: 14 de febrero de 2019

Aprobado: 13 de marzo de 2019 